\title{
Wear and Compressibility of Hybrid Composite Clutch
}

\author{
Esraa Kadhim ${ }^{1}$, Ekhlas Edan Kader ${ }^{2}$, Lutffi Zidan ${ }^{3}$ \\ 1,2,3 Mechanical Department, College of Engineering, University of Diyala \\ *corresponding author: email address: esraa_kadhim9@yahoo.com
}

\begin{abstract}
Clutch friction plate is an important part in the transmission of power in all rotating parts. To have a good view of the way it works many studies that have been made. In this research a Polymer hybrid composite have been blended to study wear and compressive ability of the composite it has been shown that sample (4) have the highest stress value with smallest strain value. sample (3) showed a convenient stress with very good strain tolerance. The study has revealed that the rate of wear and tear decreases in the case of reinforcing the base material(Novelac) which mean an increase in wear resistance, especially with the increase in the percent of kevlar fiber aramid 49 to $(40 \%-50 \%)$,where it was found that the lowest values of wear rate was in the sample (4).
\end{abstract}

Keywords: Clutch; Hybrid composite; Wear; compressibility.

Paper History: Received: 30-6-2019; Accepted:16-102019)

\section{Introduction}

A clutch is a Mechanical device that connects one rotated part with another fixed part to have the same rotational speed. It works to connect or separate the movement between the engine and the Gear box and limit the power transferred to the appropriate value .It is considered the basis for the work of most clutches on friction property, so the friction material property is important in clutch mechanism. Generally clutch is in engaged position, when peddle is pressed; clutch is disengaged that cause sudden increase in temperature. Because of friction between mating part some part of material get worn out. Problem has associated with clutch is when the force has applied on the clutch; deformation will take place due to cyclic stresses and temperature variation [1].

Wear may be defined as the progressive loss of the material from one or both of the two surface surfaces when they are under the influence of a relative movement, the wear may also be accompanied by the transfer of the material from one of the two surfaces to the other, the wear of different engineering materials is one of the most important sources of failure for the continuous parts or exposed to moving minutes at different speeds in the gas and liquid media, Regardless of the rate of wear results, wear resistance needs many properties, the important part of which is the metallurgical properties[2], the most important being the hardness and Changes in the roughness of surfaces show up in the intensity and mechanism of wear. It has been noted that an increase in roughness of a hard surface during wear of rigid polymers leads to the appearance of longitudinal plowing trenches and to abrasive wear. Rigid and brittle polymers wear abrasively even during friction on smooth surfaces. For extremely smooth surfaces, the wear rate of polymer (where adhesion is at a maximum)) is fairly high. As a number of surface roughness increases, the wear to the polymer surface decreases [3][4].

\section{Literature Review}

In (2015), R. Biczó et al., examined composite friction materials used in brake and clutch applications. These studies led to the conclusion, that inclusion of copper as metallic fillers improves all major properties of frictional materials.As for fiber reinforcements, regarding strength and modulus aramid, glass, carbon and steel can be taken into account. Aramid also has high thermal stability, good wear properties and stable coefficient of friction [5].

In (2015), Abeer M. Abdel Aziz, studied Novolac composite properties reinforced with some ceramic materials used for disc brake system .Novolac has been reinforced with materials with mechanical properties Including the use of worn disc brake.It has been concluded that the best ratio of phenol (Nov + HMTA) was $14 \%$. Novolac has been found to be suitable because it has acceptable corrosion properties. The comparison between commercially available braking pads and the best two overlays in the study showed a convergence in physical properties and performance [9].

In (2017), S. Gokulakannan, studied the usage of Poly Ether Ether Ketone based composites mixed with silicon carbide powder .It is presumed that inorganic materials like $\mathrm{Mos}_{2}$, bronze Power as fillers could successfully delay the wear life of transfer film of PEEK based composites. The composite showed a very low friction coefficient and wear rate increased in the normal applied load. Sliding distance decreases wear rate and friction decreased with the gradual increase of filler percent [7].

\section{Properties of Clutch Plate Material}

Friction clutch should have high coefficient of friction ,imperviousness to environmental condition , such as moisture,the ability to withstand high tem-peratures, together with good thermal conductivity and diffusivity ,as well as high specific heat capac-ity, high resistance to wear and compatible with the environment for the lining material characteristics to a degree that is dependent on 
the severity and service, and heigh power transmotion (torque) [10] [11].

\section{Materials Used}

The materials have used in the preparation of samples in this research are :Phenolic resins (Phenolformaldehyde resins-Novolac [Britannica]) has used as a matrix material which can be converted from soluble polymer in organic solvents to insoluble polymer using hexamethylenetetramine (HMTA), to convert phenol to molding compound has the ability to be transformed into a non-insoluble and non-fused polymer using high temperature.

Reinforcement fiber has used kevlar fiber aramid 49 that was used in many weight ratio and fiber lengths ranging from ( $4 \mathrm{~mm}-6 \mathrm{~mm})$.As series of very different materials are used to improve the friction performance, thermal conductivity, abrasion resistance and strength of the fabricated friction element. . magnesium oxide act as cure accelerators for phenolic resins. Metals iron and brass powder are added to improve the thermal conductivity. Graphite, antimonytrisulfide and molybdenum sulfide are used as lubricants and wear modifiers.Strearate zinc is used as internal lubricant,alumina oxide used to improve the friction performance,bentonite used as a filler and has been used commercial clutch powder that obtaind by crushing clutch material to powder.Ethyl alcohol is used to ensure that the material is homogeneous (not calculated from the weight ratios of the mixture because it evaporates).

\section{Preparation of the Samples}

Table 1 has showed clutch materials with specified weight , and weight ratios $\Psi$ within a specific range and depending on the equation below:

$\psi=\frac{w f}{w c} * 100 \% \quad \ldots \ldots$

$W_{c}=W_{f}+W_{m} \ldots \ldots$

Where: $(W f, W m, W c)$ represent the weight of fiber, matrix material and composite materials, respectively. .The Matrix Material (Novolac , HMTA) was mixed with Reinforcement or/ Additives/ Fillers Material (mgo, $\mathrm{Zn}(\mathrm{C} 18 \mathrm{H} 35 \mathrm{O} 2) 2, \quad \mathrm{Sb}_{2} \mathrm{~S}_{3}, \quad$ Graphite, Bentonite , $\mathrm{Cu}, \mathrm{Al}_{2} \mathrm{O}_{3}$, Commercial clutch powder , Kevlar fiber aramid 49)Together. The mixture is dissolved for using ethyl alcohol to ensure that the mixture is homogenized and leave a period until the alcohol evaporates from the mixture (At room temperature $\left(45^{\circ} \mathrm{C}\right)$ In the July month).

Table1 weight ratios of hybrid composite sample

\begin{tabular}{|c|c|c|c|c|}
\hline \multirow{2}{*}{ Material } & \multicolumn{4}{|c|}{ Sample } \\
\cline { 2 - 5 } & \multicolumn{4}{|c|}{ Components Weight Ratio (\%) } \\
\cline { 2 - 5 } & 1 & 2 & 3 & 4 \\
\hline Novolac & 11.5 & 10.5 & 8.5 & 9.5 \\
\hline HMTA & 3.5 & 3.5 & 3.5 & 3.5 \\
\hline Kevlar fiber aramid 49 & 45 & 31 & 39 & 50 \\
\hline Graphite & 3 & 4.5 & 4.25 & 4.37 \\
\hline Alumina oxide & 0.4 & 1.5 & 0.75 & 0.88 \\
\hline Antimony trisulfide & 2 & 4.5 & 4 & 3.75 \\
\hline Mgo & 2.5 & 4 & 3.2 & 2.5 \\
\hline Stearate zinc & 1 & 3 & 2.5 & 1.5 \\
\hline Commercial clutch powder & 5 & 5 & 5 & 2.5 \\
\hline Bentonite & 1 & 4.5 & 1.5 & 1.5 \\
\hline Barite & 14 & 16 & 14.8 & 14.5 \\
\hline Brass & 5.5 & 6.5 & 6.5 & 3 \\
\hline Fe & 5.5 & 6 & 6.5 & 2.5 \\
\hline
\end{tabular}

\section{Molding}

The thermal-compression machine has been used to mold the mixture, Which has manufactured in the workshops of the Department of Mechanical En-gineering and civil engineering laboratories in the Col-lege of Engineering University of Diyala, The ma-chine is consists of a $90 \mathrm{~mm}$ diameter cylindrical mold, the piston is placed above the mixture ,a moving base to fix the sample after thermal-compression pressing. The piston is placed inside the inner mold and the in-ner mold is then placed inside the heater(external mold). The heater is heated to a temperature slightly above the required temperature, after 20 minutes of time the mixture is then placed inside the inner mold and the piston is placed above it. Then a pressure of $180 \mathrm{kN}$ is applied using a compres-sion machine located in the laboratories of the De-partment of Civil Engineering University of Diyala (Italian provenance2010), and then the process of pressing samples at a temperature of $163 \mathrm{C} 0$ and a pressure of $180 \mathrm{kN}$ and a time period of 10 minutes fig.1.a show thermal compression device.Then the sample is extracted from the device and left in room atmosphere for a sufficient time (5-10 days). Fig.1.b show thermal compression prcess. 


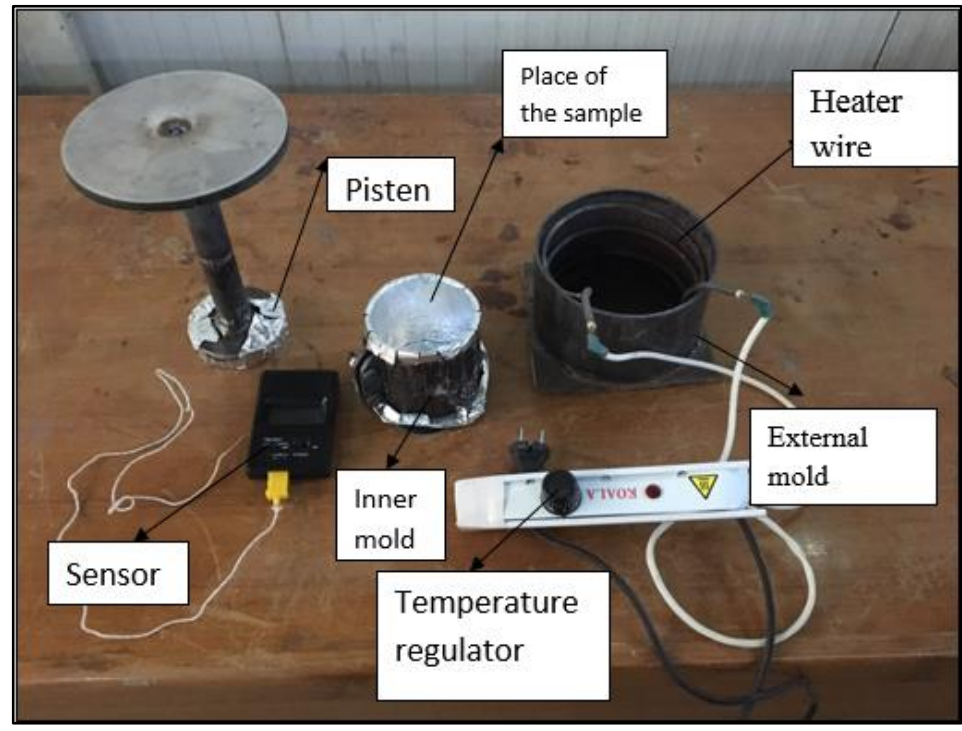

a

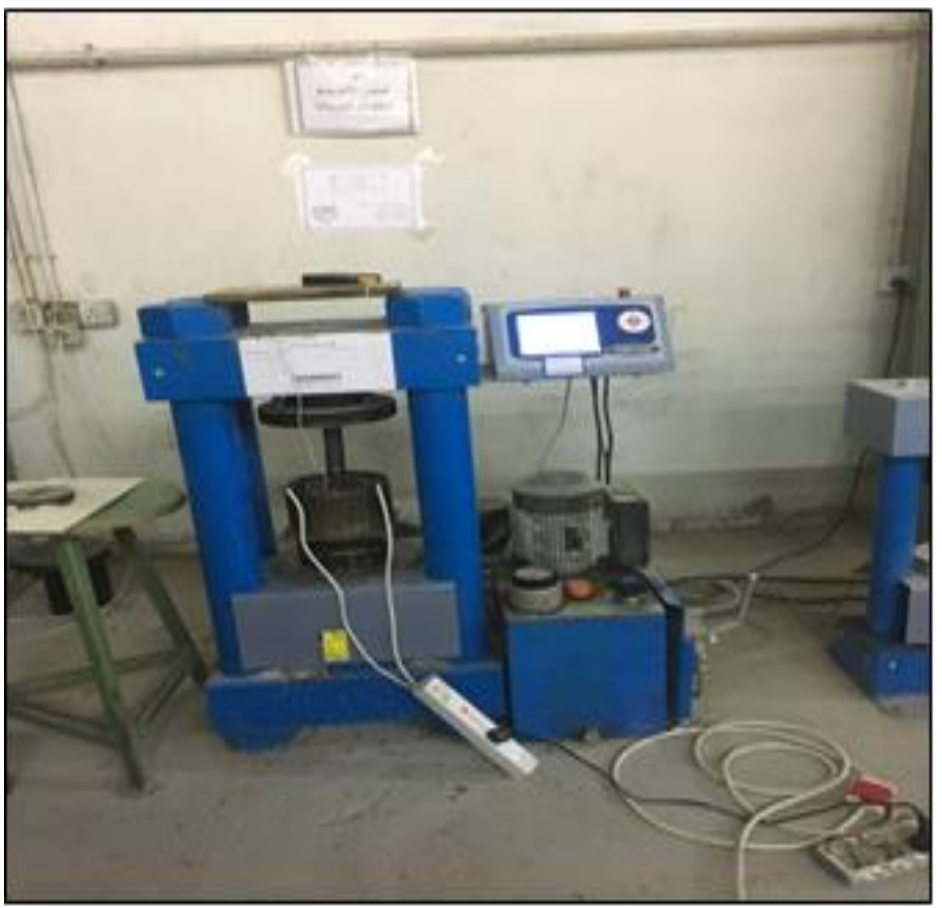

b

Figure 1: a.Thermal-compression device. b. Thermal-compression process.

\section{Compressibility Test}

For a stress-strain diagram there are two tests

The first is a tensile test and the second is a compression test, therefore the clutch sample is more susceptible to pressure than tensile. Compression testing has been accomplished simulating the clutch sample work in reality. This test is highly dependent on the density of the rein-forcing materials. It is observed that the compressive strength gives good results at low densities because high density is the main factor for acceleration in the process of sample failure, this means that low density materials have good compression resistance compared to high density materials [7]. The compression test of the material is complementary to the image of the polymer's strength and its tolerance to the conditions of use, compression is defined as the maximum stress borne by the rigid material under vertical pressure on the sample section [8].Compression resistance also depends on the method of testing. Most studies have indicated that the failure of the material depends on the way the shed load [4][1].Compression resistance can be calculat-ed using the following equation : 


$$
\text { C.S }=\mathrm{F} / \mathrm{A}
$$

C.S = compressive strength $(\mathrm{N} / \mathrm{mm} 2)$

$\mathrm{A}=$ Area of the sample section $(\mathrm{mm} 2)$

$\mathrm{F}=$ Force $(\mathrm{N})$.

\section{Wear Test}

To calculate wear rate of composite sample; pin on disc method was used. This method was adopted in because it is easy and it can be used to inference the wear rate because it gives the amount of wear debris. This method is summarized by weight of the sample before and after the test, and the difference between the two weights represents the amount of wear debris [6]. According to the weight method, the wear rate can be calculated as follows [8]:

Wear rate $(\mathrm{W} . \mathrm{R})=\Delta \mathrm{W} / \mathrm{S} . \mathrm{D}$

$\Delta \mathrm{W}=W_{b}-W_{a}$

Where:

$\Delta \mathrm{W}$ : is weight loss $(\mathrm{g})$.

$W_{b}$ : is weight of sample before operate.

$W_{a}$ : is weight of sample after operate.

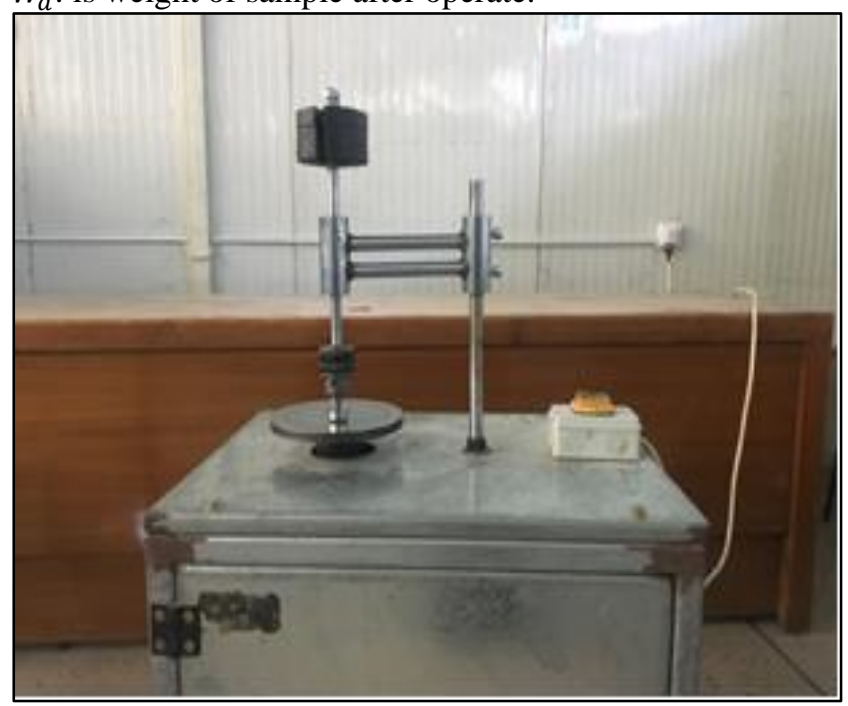

Figure 2: Wear Test Device.
S.D: is sliding distance it calculated as follows:

$S . D=t . V$

$\mathrm{t}$ : is sliding time $(\mathrm{sec})$.

$\mathrm{V}$ : is sliding velocity $(\mathrm{cm} / \mathrm{sec})$ it calculated as follows:

$\mathrm{V}=\mathrm{D} \mathrm{n} \pi$

$\mathrm{n}$ : is angular disk velocity (rpm).

$\mathrm{D}$ : is sliding diameter $(\mathrm{cm})$

The equation come as follows:

$\mathrm{V}=2 \pi \mathrm{r} . \mathrm{n} / 60(\mathrm{~cm} / \mathrm{sec})$

And, Wear rate (W.R.) $=\Delta \mathrm{W} / 2 \pi \mathrm{t}$ r.n $/ 60$

The wear measuring device used at the University of Diyala/ Mechanical Eng. Department/ in materials lab. Pin-on-disk device is popular wear testing apparatus,is shown in Fig. 2 for the purpose of obtaining contact between the sample and the disc rotor under the vertical load effect, This device consists of the electrical motor which rotates at an angular velocity, the motion is transferred from the electrical motor to the disc. The disc has an angular velocity of (720 rpm).

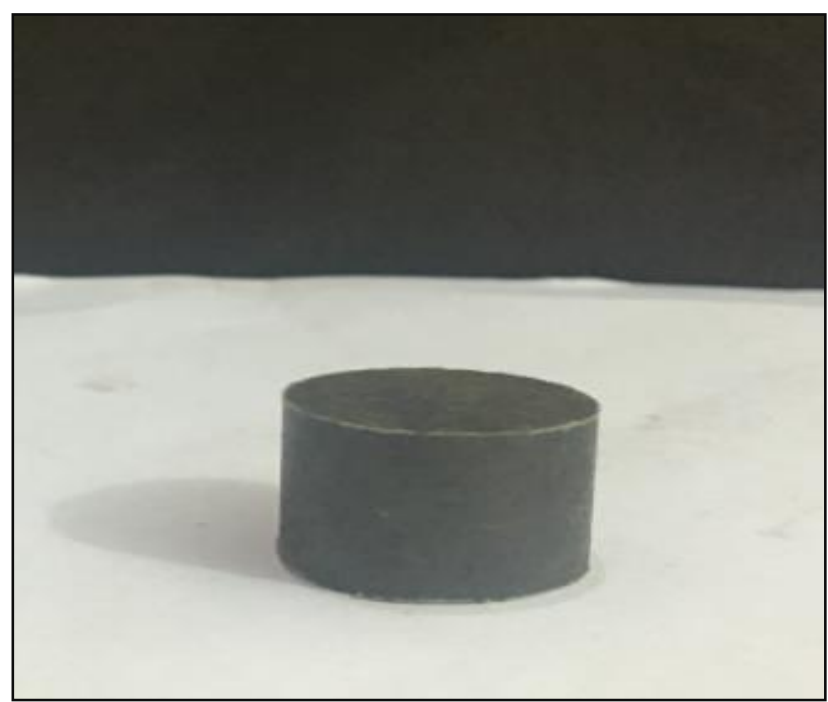

Figure 3: Wear Test Sample.

The dimensions of wear test sample was $10 \mathrm{~mm}$ diameter and $20 \mathrm{~mm}$ high show that in figure 3 .

\section{Results}

\section{Wear Test Result}

Results of wear test are listed according to the considered variable as:

\section{Effect of Applied Load}

Figure 4 show the effect of applied load on the composite blends, the values of load were taken as $(10$, $20,25,30) \mathrm{N}$ respectively. The test period was (8) minutes with $(5 \mathrm{~cm})$ sliding radius. where it was observed that the increasing the addition materials and the decreasing of fiber lead to increases of the wear rate of 
as load increases Within the limits of the sliding speed used. The explanation for this is that the rates of wear vary in their range or intensity with the change in load according to the difference in the density of the Kink bands [2] [1]. And composite particles make on obstricates to the material at removal which led to the reduce wear rate.

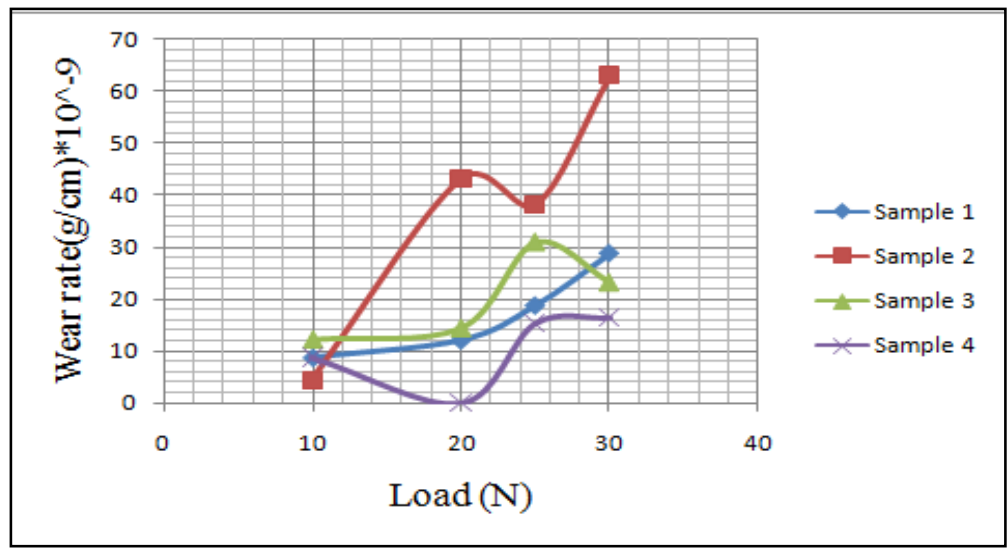

Figure 4: Effect of applied load on the composite blends.

At low load rates $(10 \mathrm{~N})$ a large removal of the resinous protrusions on the surface of the composite material due to plowing of the metal surface grooves on the composite material when sliding, with an increase in load to $(20 \mathrm{~N})$ it is noted that the Plowing decreases, this decrease due to simple fibrous protrusions By Plonghing because of fiber characteristic of shear resistance and high strength [2] [5].

\section{Effect of the Sliding Distance}

Figure 5 show the sliding distance effect on wear rates, the values of sliding radius taken as $(3.5,5,5$,
$7.5) \mathrm{cm}$ respectively. The test period was (20) minutes with (30)N load. The results showed that the rates of wear depends on the sliding distance.

Wear rate of composite material increase, as the sliding distance increased due to the increase in the value of the work performed by the friction force due to the increase of the sliding radius, this leads to a gradual shift to thermal energy that increases the rate of wear.

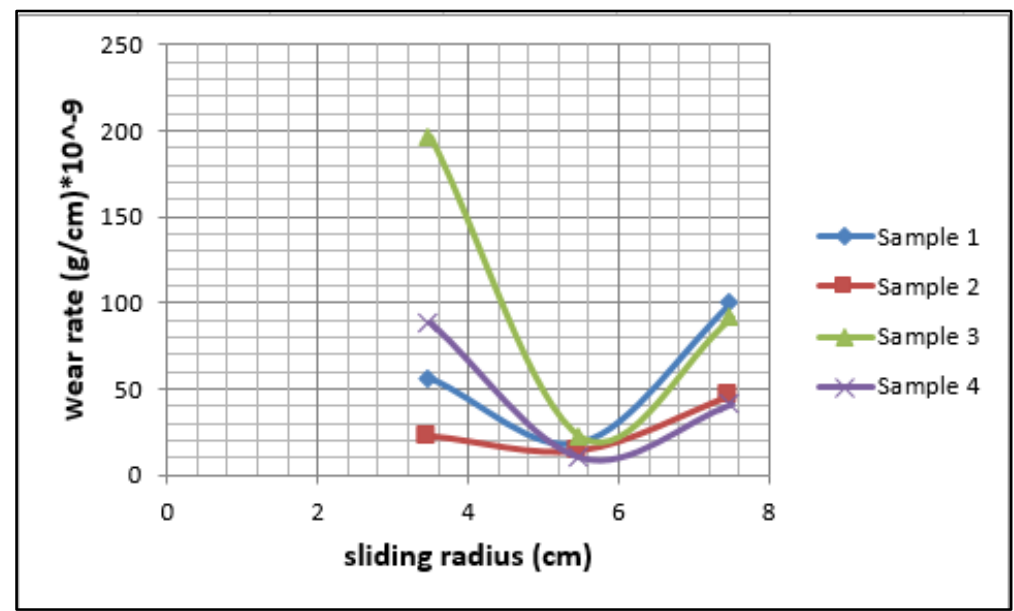

\section{Compressibility Test Result}

Figure 6 show that weight ratio $40 \%$ of the reinforcing material increases the compressive strength. When this ratio increases to $60 \%$, the compression resistance decreases as the cohesion and bonding of the overlapping material decreases with the decrease of the polymer matrix material ratio, suffice it to mention that the presence of defects generated during the
Figure 5: Sliding distance effect on wear rates.

manufacturing process has a large role in the formation of areas for the concentration of stresses, which accelerates the process of failure of the sample on the other hand, there has been a good step towards obtaining high compression resistance using high ratios of fiber, and this height represents the positive image played by these fibers because they have excellent mechanical properties. 


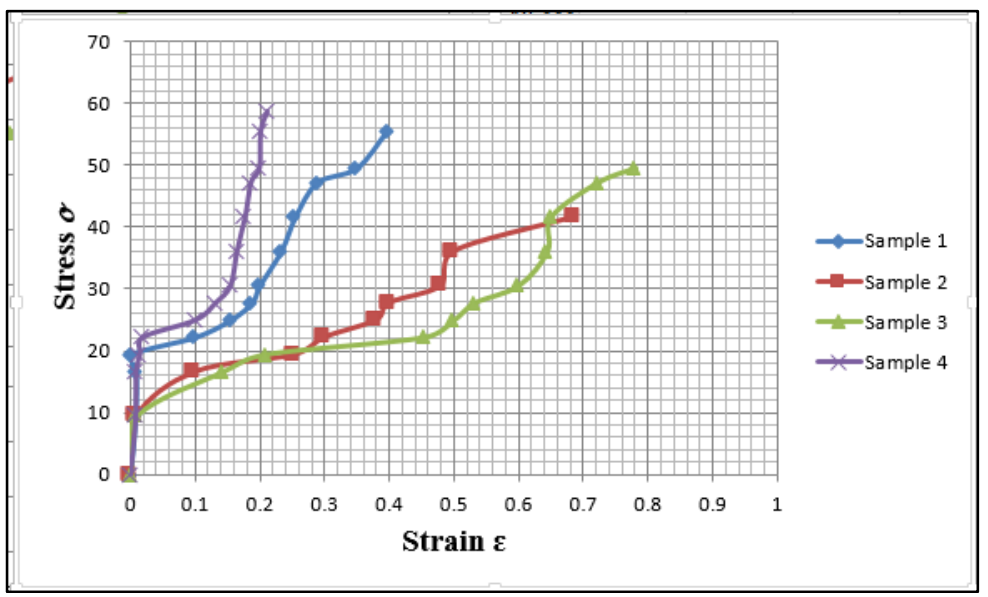

Figure 6: Stress-strain of clutch sample

\section{Conclusion}

Clutch friction plate plays an important role in torque transmission from engine to gear box. So choosing the friction plate material property is very important in designing the clutch. Due to friction between mating parts some of friction material get wear out. Torque transmission capacity of sintered-iron friction material is high and Sintered-iron material can sustain higher temperature. The following was concluded considering the experimental work:

1- Novolacresin is very suitable for making clutch lining because of its high resistance to wear ability.

2-In order to avoid the fragility of the Novolac, its structural construction should be supported by materials with good mechanical properties and good elastic properties.

3-Reinforcing materials contribute to the wear resistance of the composite material and to the requirements of clutch lining by controlling their weight ratios and the preparation process. The best performance of the hybrid composite when using Kevlar fiber aramid with $49 \%$ wt ratio.

\section{References}

[1]. Rola Abdul-Khader Abbas Al-Safi, Study the Thermal and Mechanical Properties of Novolac and his composites, M. Sc, Department of Applied Science, University of Technology, Baghdad, 2001.

[2]. Ekhlas edan kader, improving of mechanical properties of nano polymeric composite materials, Ph.D Thesis, School of Applied Science, University of Technology, Baghdad,2014.

[3]. A.M. Hameed, Development and Study of BlendBase Polymer Composites, Ph.D Thesis, School of Applied Science, University of Technology, Baghdad, 2006.

[4]. Huda Jabbar Abdul Hussein, Resistant wear and tear for polymeric thermocouple mixtures, M.sc,
Department of Applied Science, University of Technology, Baghdad, 2008.

[5]. Biczó et al, Composite Friction Materials for Brakes and Clutches, Buletin Ştiinţific, Vol.No.3 (2015) pp:21-26.

[6]. Abeer Majid A, Study Novolac Composite Properties Reinforced with Some Ceramic Materials Used For Disc Brake System, M. Sc, Department of Applied Science, University of Technology, Baghdad, 2015.

[7]. Gokulakannan, A Review on Wear Behaviour Of Clutch Plate Made Of PEEK, Journal Of Science And Technology (JST), Volume 2, Issue 3 (2017) PP 19- 26.

[8]. Bayer, R. G. , Mechanical Wear Fundamentals and Testing, $2^{\text {ed }}$ Edition, Marcel and Dekker, Inc., USA, 2004.

[9]. D.Hull, An Introduction to Composite Materials, Cambridge University press, England, 1981.

[10]. Richard G.Budynas \& J.KeithNisbett, Shigley's Mechanical Engineering Design, (Ninth Edition), Published by McGraw-Hill,2011.

[11]. Azad M. Saber \& Khatoon Y. Ibrahim , Experimental Stress Analysis For Woven Carbon, Glass, and Kevlar Laminate Shells, Diyala Journal of Engineering Sciences, vol.11 No:4 (2018) pp:60-66. 